\title{
Scheduling of Domestic Water Heater Power Demand for Maximizing PV Self- Consumption Using Model Predictive Control
}

Sossan, Fabrizio; Kosek, Anna Magdalena; Martinenas, Sergejus; Marinelli, Mattia; Bindner, Henrik W.

Published in:

Proceedings of ISGT Europe 2013

Link to article, DOI:

10.1109/ISGTEurope.2013.6695317

Publication date:

2013

Link back to DTU Orbit

Citation (APA):

Sossan, F., Kosek, A. M., Martinenas, S., Marinelli, M., \& Bindner, H. W. (2013). Scheduling of Domestic Water Heater Power Demand for Maximizing PV Self-Consumption Using Model Predictive Control. In Proceedings of ISGT Europe 2013 IEEE. https://doi.org/10.1109/ISGTEurope.2013.6695317

\section{General rights}

Copyright and moral rights for the publications made accessible in the public portal are retained by the authors and/or other copyright owners and it is a condition of accessing publications that users recognise and abide by the legal requirements associated with these rights.

- Users may download and print one copy of any publication from the public portal for the purpose of private study or research.

- You may not further distribute the material or use it for any profit-making activity or commercial gain

- You may freely distribute the URL identifying the publication in the public portal 


\title{
Scheduling of Domestic Water Heater Power Demand for Maximizing PV Self-Consumption Using Model Predictive Control
}

\author{
Fabrizio Sossan, Anna Magdalena Kosek, Sergejus Martinenas, Mattia Marinelli, Henrik Bindner \\ Center for Electric Power and Energy \\ Technical University of Denmark \\ 4000 Roskilde, Denmark
}

\{faso, amko, smar, matm, hwbi\}@elektro.dtu.dk

\begin{abstract}
This paper presents a model predictive control (MPC) strategy for maximizing photo-voltaic (PV) selfconsumption in a household context exploiting the flexible demand of an electric water heater. The predictive controller uses a water heater model and forecast of the hot water consumption in order to predict the future temperature of the water and it manages its state (on and off) according to the forecasted PV production, which are computed starting from forecast of the solar irradiance. Simulations for the proof of concept and for validating the proposed control strategy are proposed. Results of the control approach are compared with a traditional thermostatic controller using historical measurements of a $10 \mathrm{~kW}$ PV installation. Economic results based on the Italian self consumption tariffs are also reported. The model of the water heater complex is a mixed grey and white box and its parameters have been estimated using a real water heater device.
\end{abstract}

Keywords - Smart grids, Power demand, Solar generation, Demand Side Management

\section{INTRODUCTION}

In the last decade, worldwide evolution of installed photovoltaic capacity shows an exponential growth with an increase of nearly $70 \%$ in Europe between 2010 and 2011 given by an increment of $30 \mathrm{GW}$ of new installations [1]. According to [1], the PV installation capacity in Europe is expected to increase in the incoming years, because of national government targets and convenient feed-in tariffs. In 2009, Germany introduced tariffs for promoting self-consumption allowing users to receive incentives for each consumed watt during PV production periods [2], [3]. The same kind of incentive has been introduced in Italy in 2013.

The photo-voltaic energy self-consumption is relevant for allowing the transition towards a more efficient power system, improving power balance, voltage stability and reduction of power losses. Several solutions for controlling a battery storage to absorb the excess of PV production and reuse it during peak hours have been proposed. Braun et. al. [4] presents a energy management strategy using a PV installation coupled with lithium batteries. [5] proposes a centralized controller that optimizes the use of lead acid batteries taking into account consumption patterns and schedule of common domestic white goods while [6] proposes a battery control strategy for absorbing fluctuations of renewable sources. Few attempts of absorbing PV production using so-called Demand Side Resources have been proposed. DSRs are electric loads which have an intrinsic natural flexibility due, for example, to thermal inertia. DSRs allow to defer electric power usage without compromising the quality of the services they are supplying to the users and they are generally proposed as a resource for supporting power system regulating power [7] or frequency regulation [8].

In this paper, a MPC strategy for scheduling the consumption of an electric water heater according the forecasted PV production is presented. The choice of the demand side unit to control has been done according to the fact that the power required by water heater is not correlated with sun irradiance. In case for example of [9], the power demand is negatively correlated with the sun irradiance, because the sun contributes to warm the building envelope, and therefore the self-consumption strategy might be not effective. On the contrary, air conditioning units would be very convenient for PV self-consumption policies since their power demand is positively correlated with sun irradiance during the warm season. The advantage of exploiting flexible demand other than batteries, it is that some flexible units are already present at household level and it is definitely worth investigating their usability before considering to place new storage devices.

The model predictive control strategy uses a grey box model of a single element electric water heater whose parameters have been estimated from a real device. An optimization algorithm is finally used for scheduling the power consumption of the heater in order to use electric energy when photo-voltaic power is available and to respect user comfort (i.e., hot water should always be available when required). Simulation results of the receding horizon MPC strategy are proposed. Predictive control is compared with a traditional thermostatic controller and economic results based on real self-consumption and feed in tariffs are proposed.

The paper is organized as follows: Section II presents the water heater model, it formulates the optimization problem needed for realizing the MPC strategy and it shows how the controller is applied for controlling the water heater. Section III contains simulation results of the receding horizon MPC strategy. Section IV presents discussion and conclusions are finally reported in Section V. 


\section{Methods}

The target of the proposed control strategy is to maximize photo-voltaic self-consumption, shifting the power usage of a domestic electric water heater. The optimal control problem is formulated as linear optimization and the cost expression is shown in Eq. 1.

$$
\begin{array}{cl}
\min _{P_{e}} & \sum_{i}^{N}\left|\frac{\max \left(P^{s}\right)-P_{i}^{s}}{\max \left(P^{s}\right)}\right| P_{i}^{e} \\
\text { subject to } & T_{i+1}=f\left(T_{i}, T_{i}^{\text {room }}, q_{i}, T_{i}^{\text {inlet }}, P_{i}^{e}\right) \\
& T_{\min } \leq T_{i} \leq T_{\max } \wedge P_{\min }^{e} \leq P_{i}^{e} \leq P_{\max }^{e}
\end{array}
$$

Index $i$ refers to a discrete time instant. The time series $P^{s}$ is the forecast for the produced PV energy. Photo-voltaic forecast model is introduced in subsection II-B. $P^{e}$ is the power consumption profile of the water heater and it is the target variable for the optimization process. Constraint 2 is evaluated using the mathematical model of the electric water heater, which is presented in paragraph II-A: $T$ is the average temperature of the water inside the tank, $T^{\text {room }}$ is the temperature of the room where the heater is placed and $T^{\text {inlet }}$ is the temperature of the cold water which replaces the consumed hot water; quantity $q$ is the amount of consumed hot tap water. For this simulation, a static pattern for the hot water consumption profile is used [10]. The same pattern has been used as forecast (i.e., forecast are assumed perfect). Inequalities 3 set the upper and lower bounds for the water temperature and limit the electric power consumption of the heater. $N$ is the length in number of discrete time steps of the optimization horizon length, the receding time horizon has been chosen to be 12 hours in order to encompass the day ahead cycle of PV production.

The pseudo-code which shows how the MPC strategy is applied is shown in listing 1. The MPC problem is solved at each iteration for the whole receding horizon length (12 hours) but only the first control is actuated at each cycle. The sampling time is 15 minutes.

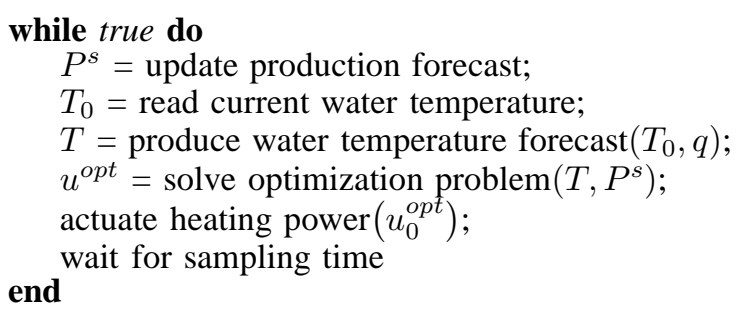

Algorithm 1: MPC receding horizon formulation

The output of the MPC is the energy that the heater should consume in the time frame. In case of a real device, the on-off state could be modulated in order to obtain the right amount of energy. This policy is still acceptable because the self-consumption is primarily about maximizing the amount of energy which is consumed and not following a precise power profile.

\section{A. Water heater model}

In this section a model for a single element electric water heater is presented. Thermal stratification of the water due to buoyancy effect is not described in this model.
Thermal loss towards the environment: Thermal loss to external environment is due to heat conduction loss through the surface of the tank and the natural convection which moves heat from the tank surface to the environment. Heat loss $Q$ is modeled as heat conduction through the surface of the water tank:

$$
Q(t)=-A \frac{T(t)-T^{\text {room }}(t)}{R}
$$

where $A$ is the surface of the tank, $R$ the thermal resistance of the insulation material and $T^{\text {room }}$ the ambient temperature. It is assumed that the room temperature is not affected by the heater thermal loss (bigger thermal inertia).

Thermal loss due to water consumption: Given an amount of water with mass $m$ which is consumed in the time interval $\Delta T$ and replaced in the tank by new water at temperature $T^{i n}$, the new average temperature of the water in the tank $T_{i+1}$ can be expressed as combination of the temperatures of cold and hot water weighted on the mass ratio ( $m_{t}$ is the mass of water associated with the volume of the heater tank):

$$
\begin{aligned}
& T_{i+1}=\frac{m}{m_{t}} T^{i n}+\frac{m_{t}-m}{m_{t}} T_{i} \\
& T_{i+1}-T_{i}=\frac{m}{m_{t}}\left(T^{i n}-T_{i}\right)
\end{aligned}
$$

Assuming the mass flow rate $q(t)$ piecewise constant, the mass can be expressed as $m=q(t) \Delta t$ where $\Delta t$ is the sampling time and Eq. 5 becomes:

$$
\frac{T_{i+1}-T_{i}}{\Delta t}=\frac{q_{i}}{m_{t}}\left(T^{i n}-T_{i}\right)
$$

and the contribution in terms of heat flux is:

$$
Q(t)=C_{p} q(t)\left(T^{i n}(t)-T_{i}(t)\right)
$$

Contribution from heating element: The heat to the water is supplied through the Joule losses in the heating conductor, so:

$$
Q^{i n}(t)=P_{e}(t)
$$

Final model is obtained merging the contribution of Eq. 4, Eq. 6 and Eq. 7:

$$
\begin{aligned}
C_{p} m_{t} \dot{T}(t)= & -A \frac{T(t)-T^{\text {room }}(t)}{R}+ \\
& +C_{p} q(t)\left(T^{i n}(t)-T_{i}(t)\right)+P(t)
\end{aligned}
$$

Reorganizing the terms yields to:

$$
\begin{aligned}
\dot{T}(t)= & -A \frac{T(t)-T^{r o o m}(t)}{R C_{p} m_{t}}+ \\
& +\frac{T^{i n}(t)-T_{i}(t)}{m_{t}} q(t)+\frac{P(t)}{C_{p} m_{t}}
\end{aligned}
$$

Defining the thermal mass $C_{w}=C_{p} m_{t}$ and a lumped coefficient $R_{e}=A / R$ for accounting the conduction losses through the water tank, Eq. 9 becomes:

$$
\begin{aligned}
\dot{T}(t)= & -\frac{T(t)-T^{\text {room }}(t)}{R_{e} C_{w}}+ \\
& +\frac{T^{i n}(t)-T(t)}{C_{w} / C_{p}} q(t)+\frac{P(t)}{C}
\end{aligned}
$$


which can be rewritten as:

$$
\begin{aligned}
\dot{T}(t)= & \left(-\frac{1}{R_{e} C_{w}}-\frac{q(t)}{C_{w} / C_{p}}\right) T(t)+ \\
& +\frac{1}{C_{w}} P_{e}(t)+\frac{1}{R_{e} C_{w}} T^{\text {room }}+\frac{q(t)}{C_{w} / C_{p}} T^{\text {in }}(t)
\end{aligned}
$$

a time variant multiple input single output model. Analogue model has been described in [11] and [12]. For performing simulation, Eq. 10 is discretized with a sampling time of $900 \mathrm{~s}$.

A mixed white and grey box modelling criteria has been adopted for assigning the values of thermal capacitance and resistance of the water tank model. The thermal capacitance has been assigned considering the water as the predominant thermal mass of the whole water heater complex, so:

$$
C_{w}=\frac{V_{t}}{1000} \rho C_{p}
$$

where $V_{t}$ is the capacity in liters of the tank $(301), \rho$ is the water density $\left(1000 \mathrm{~kg} \cdot \mathrm{m}^{-3}\right)$ and $C_{p}$ is the specific heat at constant pressure $\left(4183 \mathrm{~J} \cdot \mathrm{kg}^{-1} \cdot \mathrm{K}^{-1}\right)$. The thermal conductivity of the tank has been estimated using temperature measurements of the water inside the tank and with a simple numeric procedure which consists in measuring the electric power (without any hot water tap consumption) and divide its average by the difference between the average water temperature and the room temperature. So, the thermal resistance $R_{e}$ of Eq. 10 is:

$$
R_{e}=\frac{\bar{T}-T^{\text {room }}}{\bar{P}_{e}}
$$

\section{B. PV production forecast model}

The production of the PV plant is predicted starting from forecast for the sun irradiance on the horizontal plan and translated into production values using a PV model. Solar irradiance forecast has one hour resolution and it is provided by DTU Wind Energy, Meteorology Section [3] through an FTP server. The input-output diagram of the PV model is shown in Fig. 1. Geographical information is needed by the model for computing the azimuth and the altitude of the sun in the sky. Given the installation characteristics of the plant, the model computes the quantity of solar radiation which is incident to the panel. Finally a thermal characterization of the PV cells, which is function of ambient air temperature, sun radiation and wind speed, is used for computing the losses and indeed the efficiency of the photo-voltaic effect.

\section{Simulation set-up}

The simulations here presented are used for showing the capability of the model predictive controller to move the consumption of the heater during hours with PV production. The MPC uses solar irradiance forecast relative to $4^{\text {th }}$ May 2013. Water consumption profile is from [10] and it has been resized for the need of two people (considering the small size of the water boiler in analysis). Water consumption forecast are the same as the consumption profile and, indeed, they are assumed to be perfect. In order to evaluate the performances of the MPC strategy, the water heater consumption profile is compared with a traditional thermostatic controller and real

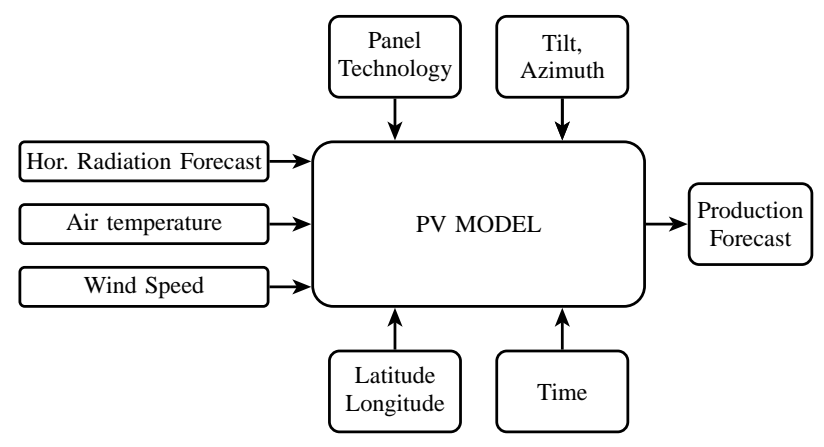

Fig. 1. The PV model allowing to obtain the forecast for the photo-voltaic production.

production data for the same day of a $10 \mathrm{~kW}$ SYSLAB PV plant ${ }^{1}$ - normalized and referred to a smaller $2 \mathrm{~kW}$ PV installation - are used for evaluating the economic income for adopting such solution using Italian feed-in and selfconsumption tariffs.

A summary with the relevant information for the simulation is reported in Table I.

TABLE I. Simulation SETUP

\begin{tabular}{l|l|l} 
Component & Attribute & Value \\
\hline \hline PV plant & Nominal power & $2 \mathrm{~kW}$ \\
\hline \multirow{3}{*}{ Water Heater Model } & Nominal power & $1.26 \mathrm{~kW}$ \\
& Tank capacity & 301 \\
& $\mathrm{R}$ (model parameter) & $2 \mathrm{~K} \cdot \mathrm{W}^{-1}$ \\
\hline Thermostatic controller & Temperature set point & $55 \pm 5^{\circ} \mathrm{C}$ \\
\hline MPC controller & Optimization length & 12 hours
\end{tabular}

\section{RESULTS}

Fig. 2 compares the forecasted PV production with a real production profile, obtained normalizing the measurements from a $10 \mathrm{~kW}$ PV ground installation. Production forecast are computed starting from forecast of the sun irradiance on the horizontal plan which comes with a resolution of one hour. In this case the production forecast is not able to detect local drop of power (due to fast clouds passage) but, for the day under consideration, it is able to capture the average component especially during the central part of the day.

Fig. 3 compares the power consumption profiles of the heater obtained by the two controllers, MPC and thermostatic. The yellow surface shows the measured and normalized PV production.

Fig. 4 shows the electric energy which has been bought from the grid in order to satisfy the demand required by the two water heater controllers.

Fig. 5 presents the portion of electric energy produced by the PV which has been self consumed by the electric water heater.

Fig. 6 shows the part of PV production which has been sold to the national grid because it has not been not self consumed.

${ }^{1}$ SYSLAB is laboratory for intelligent distributed power systems at Technical University of Denmark, part of PowerLabDK (www.powerlab.dk). 


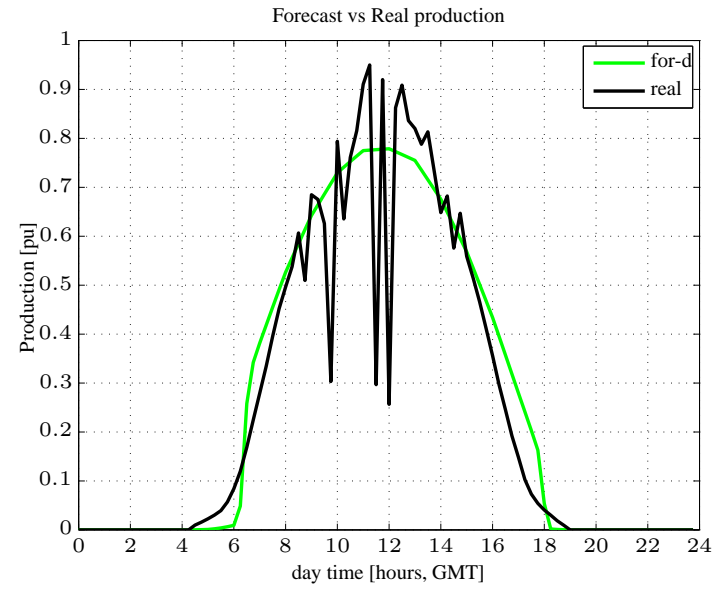

Fig. 2. Forecasted production against real production based on data for $4^{\text {th }}$, May 2013.

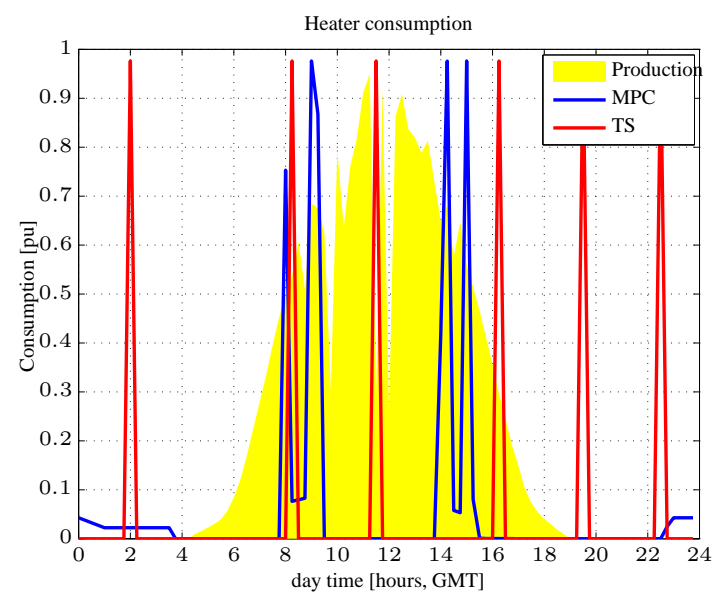

Fig. 3. Power consumption profiles for the two control strategies against the absolute value PV production. Values are in per unit.

Fig. 7 shows the average temperature of the water inside the tank of the water heater for the two temperature control algorithms along with the water consumption profile on the right axis.

Table II shows the composition of the energy demand in terms of energy bought or self consumed and the amount of energy sold to the grid for each control algorithm. An estimation of the energy bill - referred to the day in analysis - produced by each controller is also given in the last column. it is evaluated using the Italian tariffs for PV feedin and self-consumption as a reference. The assumed tariffs are [€- $\mathrm{kWh}^{-1}$ ]: 0.23 for consumption [13], 0.20 for PV production and 0.126 for self consumed energy [14].

TABLE II. SUMMARY OF CONTROLLERS OPERATIONS ON 24 HOURS SIMULATION

\begin{tabular}{lcccc} 
Controller & Energy sold & Energy bought & Self consumed & Energy bill \\
\hline \hline Thermostat & $11.86 \mathrm{kWh}$ & $1.28 \mathrm{kWh}$ & $0.57 \mathrm{kWh}$ & $2.31 €$ \\
\hline MPC & $10.75 \mathrm{kWh}$ & $0.21 \mathrm{kWh}$ & $1.67 \mathrm{kWh}$ & $2.15 €$ \\
\hline
\end{tabular}

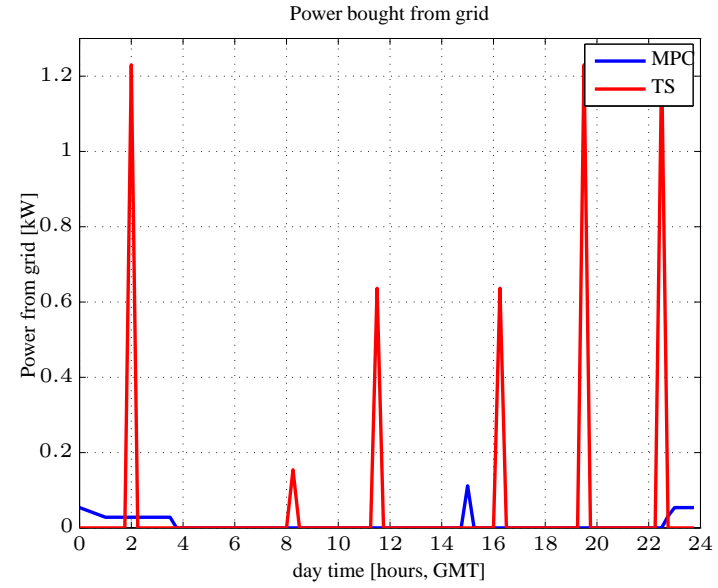

Fig. 4. Instant power which is bought from the grid in case of traditional thermostatic controller, red line, and predictive control strategy, blue line.

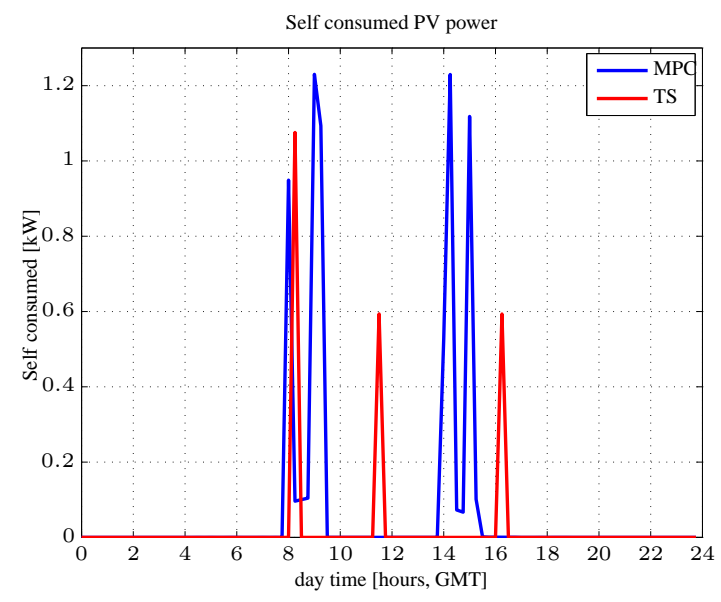

Fig. 5. Self consumed PV power for traditional thermostatic controller, red line, and predictive control strategy, blue line.

\section{Discussion}

Table II shows that the proposed MPC strategy increases to $297 \%$ the amount of active power which is consumed by the water heater during the time with PV production. The PV production forecast, Fig. 3, are able to detect the average component of the PV real production. Fast changes in the PV production profile cannot be captured because the original solar irradiance forecast are given with a resolution of one hour. The amount of money which the MPC allowed to save is $0.16 €$ on a time span of 24 hours and considering the condition as the day in analysis. For the analyzed day, the capacity factor has been 26\%: considering an annual capacity factor of $8 \%$, it can be assumed, ideally, to dispose of 112 days with an analogue production profile; assuming also the same quality for the forecast both for PV production and water consumption, the annual ideal economic revenue would be around $18 €$.

Fig. 6 shows that the flexibility in the power demand of the electric water heater in analysis (capacity $30 \mathrm{l}$ ) is definitely not enough for absorbing all the PV production. Increasing the size of the tank would increase the flexibility of the system because of the greater thermal inertia. Enlarging the 


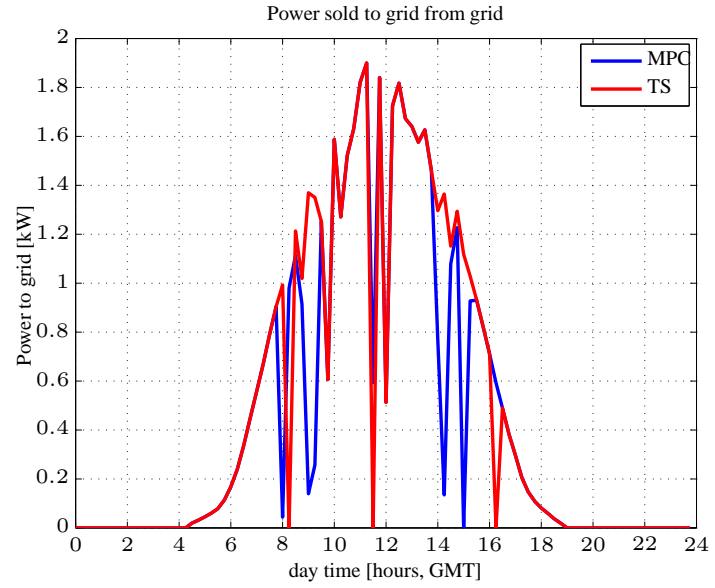

Fig. 6. PV power that has been sold to the grid in case of traditional thermostatic controller, red line, and predictive control strategy, blue line.

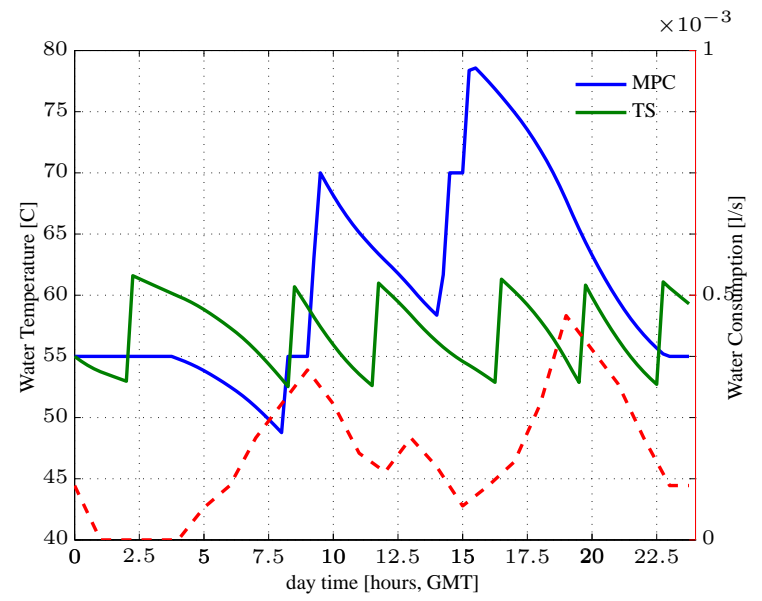

Fig. 7. Average temperature of the water inside the tank for the MPC controller and the thermostatic one. On the right axis the water consumption profile used for simulation.

range of allowed hot water temperature would also concur to increase the flexibility of the system. It is worth noting that the controller algorithm does not use the information about the real time production of the PV panel, i.e., the MPC strategy is based uniquely on the irradiance forecast and it is not corrected accounting for the current production. This setup reduces the complexity of the system because it does not require communication between the PV inverter and the MPC controller. Considering the instantaneous PV prediction error, even if it increases the complexity of the system, could be beneficial for producing better results for forecasts with a large error.

Fig. 7 shows how the MPC controller exploits the thermal inertia of the water for absorbing the production from the PV installation. When no PV production is available, the MPC let the water temperature to settle at $55^{\circ} \mathrm{C}$ : whenever the $\mathrm{PV}$ installation is producing, the MPC demands more electric power to be consumed in order to increase the temperature of the water and have it ready for consumption for longer time. At time $t=2.5 \mathrm{~h}$ the temperature of the water drops to $50^{\circ} \mathrm{C}$ because the lower temperature constraint is implemented as a soft one in the cost function and, therefore, the controller allows the water temperature to go below the lower limit when it foresees PV production in the immediate future.

\section{CONCLUSIONS}

This paper presents a model predictive control strategy for maximizing PV self-consumption exploiting the flexible demand of an electric water heater. The proposed control approach has been tested in simulation using sun irradiance forecast and real production data. Simulations showed that the MPC controller is able to move the consumption of the heater during the period when there is production from the PV plant. A comparison with a traditional thermostatic controller showed a energy bill reduced of $15 \%$ (according Italian feed-in and self-consumption tariffs) for a total save of around $0.15 €$ for the day considered for simulations. The energy self consumed by the MPC is raised to around $300 \%$ than the thermostatic controller. Such results represent a good achievement in terms of self consumed power if considered that an electric water heater is a device which is commonly present in a household context.

\section{REFERENCES}

[1] "Global market outlook for photovoltaic until 2016," tech. rep., EPIA, European Photovoltaic Industry Association, May 2012.

[2] T. Drizard, "German energy policy: reconciling energy storage and feedin tariffs through self-consumption tariffs," 2009.

[3] A. Hahmann, D. Rostkier-Edelstein, T. Warner, F. Vandenberghe, Y. Liu, R. Babarsky, and S. Swerdlin, "A reanalysis system for the generation of mesoscale climatographies,” vol. 49, pp. 954-972, May 2010.

[4] M. Braun, M. Budenbender, Z. Perrin, D. Feng, and Magnor, "Photovoltaic self-consumption in Germany," in 24th European Photovoltaic Solar Energy Conference, September 2009.

[5] E. Castillo-Cagigal, A. Caamao-Martn, D. Gutirrez, F. Masa-Bote, J. Monasterio, E. Porro, J. Matallanas, and Jimnez-Leube, "Selfconsumption of pv electricity with active demand side management: The gedelos-pv system," in 25th European Photovoltaic Solar Energy Conference, September 2010.

[6] S. Grillo, M. Marinelli, S. Massucco, and F. Silvestro, "Optimal management strategy of a battery-based storage system to improve renewable energy integration in distribution networks," Smart Grid, IEEE Transactions on, vol. 3, no. 2, pp. 950-958, 2012.

[7] F. Sossan and H. Bindner, "Evaluation of the performance of indirect control of many dsrs using hardware-in-the-loop simulations," in $C D C$, 2012 Maui, HI, US, December 2012.

[8] P. Douglass, R. Garcia-Valle, P. Nyeng, J. Ostergaard, and M. Togeby, "Smart demand for frequency regulation: Experimental results," Smart Grid, IEEE Transactions on, vol. PP, no. 99, pp. 1-8, 2013.

[9] Y. Zong, L. Mihet-Popa, D. Kullmann, A. Thavlov, O. Gehrke, and H. Bindner, "Model predictive controller for active demand side management with pv self-consumption in an intelligent building," in 3rd IEEE PES Innovative Smart Grid Technologies Europe (ISGT Europe), Berlin, September 2012.

[10] S. Kalogirou and Y. Tripanagnostopoulos, "Hybrid pv/t solar systems for domestic hot water and electricity production," Energy Conversion and Management, vol. 47, no. 1819, pp. 3368 - 3382, 2006.

[11] P. Dolan, M. Nehrir, and V. Gerez, "Development of a monte carlo based aggregate model for residential electric water heater loads," Electric Power Systems Research, vol. 36, no. 1, pp. 29 - 35, 1996.

[12] M. Nehrir, R. Jia, D. Pierre, and D. Hammerstrom, "Power management of aggregate electric water heater loads by voltage control," in Power Engineering Society General Meeting, 2007. IEEE, pp. 1-6, 2007.

[13] Eurostat, "Household electricity prices including all taxes.," May 2013.

[14] Gestore Servizi Energetici, "Quinto conto energia," 2012. 